RADIO INTERFACE SYSTEM PLANNING FOR GSM/GPRS/UMTS 


\section{RADIO INTERFACE SYSTEM PLANNING FOR}

\section{GSM/GPRS/UMTS}

By

Jukka Lempiäinen

Matti Manninen 
eBook ISBN: $\quad$ 0-306-47319-4

Print ISBN: $\quad 0-792-37516-5$

(C2002 Kluwer Academic Publishers

New York, Boston, Dordrecht, London, Moscow

All rights reserved

No part of this eBook may be reproduced or transmitted in any form or by any means, electronic, mechanical, recording, or otherwise, without written consent from the Publisher

Created in the United States of America

Visit Kluwer Online at:

http://www.kluweronline.com

and Kluwer's eBookstore at:

http://www.ebooks.kluweronline.com 
To my wife Tia,

to my parents Irene and Keijo,

to my brother Jarmo in memoriam.

\section{J. Lempiäinen}

To my wife Marika.

M. Manninen 


\section{TABLE OF CONTENTS}

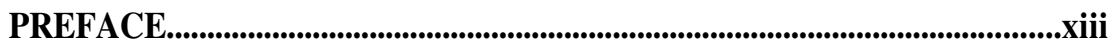

1. INTRODUCTION- RADIO PROPAGATION ENVIRONMENT ......2

1.1 DEFINITION OF THE RADIO NETWORK SYSTEM........................2

1.1.1 Coverage terminology and definitions ..........................................4

1.1.2 Capacity terminology and definitions......................................... 5

1.2 CELLULAR RADIO NETWORK ...................................................... 6

1.2.1 Cellular concept............................................................................ 6

1.2.2 Capacity, coverage and quality of service..................................

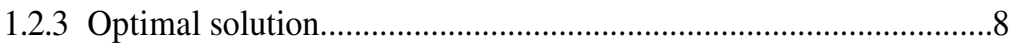

1.3 RADIO PROPAGATION ENVIRONMENT ........................................

1.3.1 Radio propagation parameters related to the environment..........10

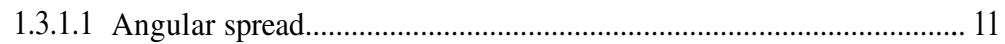

1.3.1.2 Multipath propagation and delay spread.......................................... 12

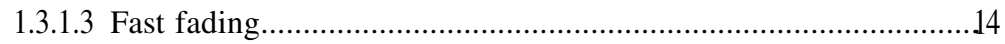

1.3.1.4 Slow fading............................................................... 17

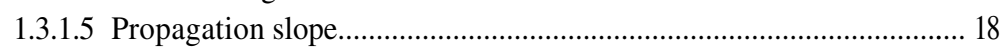

1.3.2 Characteristics of radio propagation environments.................. 20

1.4 NETWORK EVOLUTION PATH.................................................. 22

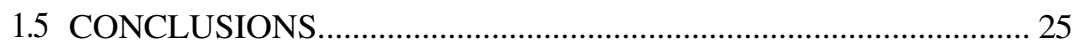

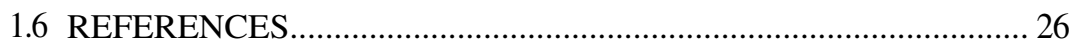

2. RADIO SYSTEM PLANNING PROCESS.............................................28

2.1 RADIO SYSTEM PLANNING PHASES ......................................... 28

2.1.1 Dimensioning....................................................................... 30

2.1.2 Detailed radio planning.......................................................... 31

2.1.2.1 Configuration planning..................................................................... 32

2.1.2.2 Coverage planning......................................................................... 33

2.1.2.3 Capacity and frequency planning................................................... 35

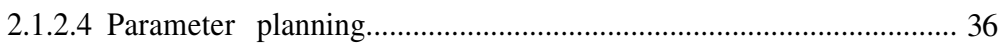

2.1.3 Optimisation and monitoring ............................................... 36

2.1.4 Radio system planning process documentation...................... 38

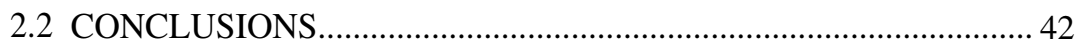


3. CONFIGURATION PLANNING AND POWER BUDGET

3.1 GENERAL POWER BUDGET................................................... 44

3.1.1 Base station and mobile station transmission power .................. 47

3.1.2 Base station and mobile station sensitivities........................... 48

3.1.2.1 Types of environment.................................................................... 48

3.1.2.2 Base station sensitivity and diversity reception....................................49

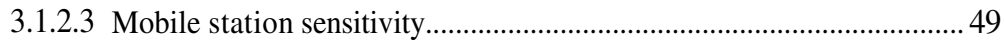

3.1.3 Combiner and receiving multicoupler losses............................ 49

3.1.4 Base station antennas............................................................ 50

3.1.5 Base station antenna installations.......................................... 53

3.1.6 Mobile station antennas.......................................................... 54

3.1.7 Base station cables and connectors .......................................... 55

3.1.8 Mobile station cables and connectors......................................... 56

3.2 POWER BUDGET AND ACCESSORY ELEMENTS.............................56

3.2.1 Power budget balance.............................................................. 56

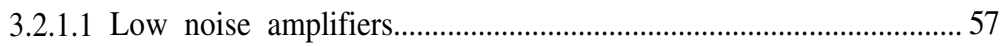

3.2.1.2 Diversity reception at the base station receiving end......................... 59

3.2.1.3 Diversity reception and radio propagation environment.................... 61

3.2.1.4 Performance of deployed diversity techniques..................................... 61

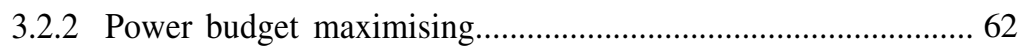

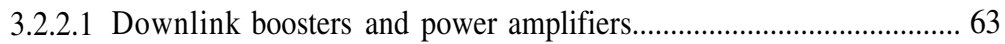

3.2.2.2 Frequency hopping and power budget........................................... 65

3.2.2.3 Single and multi band antenna line configurations ................................66

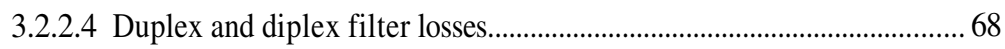

3.2.2.5 Power budget margins.......................................................................... 69

3.3 COVERAGE AND CAPACITY OPTIMIZED CONFIGURATIONS 71

3.4 CONCLUSIONS …........................................................................... 72

3.5 REFERENCES......................................................................... 73

4. COVERAGE PLANNING CRITERIA .........................................................76

4.1 LOCATION PROBABILITIES AND FADING MARGINS............. 76

4.1.1 Slow (log-normal) fading and standard deviation..................... 76

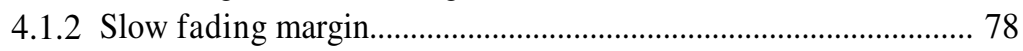

4.1.3 Point location probability......................................................... 80

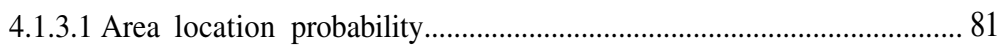

4.1.4 Multiple server location probability....................................... 84

4.2 BUILDING AND VEHICLE PENETRATION .................................. 86

4.3 OTHER LOSSES AND MARGINS............................................. 88 


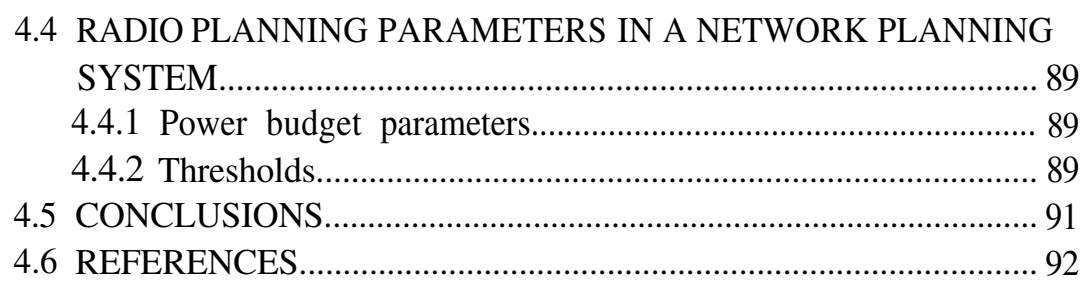

5. RADIO PROPAGATION PREDICTION ..............................................94

5.1 ELEMENTARY PROPAGATION FUNDAMENTALS..................... 94

5.1.1 Reflections, diffractions, absorptions........................................ 95

5.2 MACRO LEVEL MODELS........................................................ 98

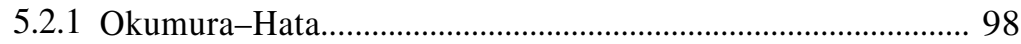

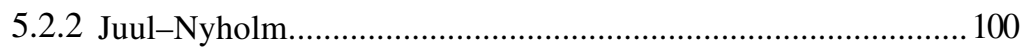

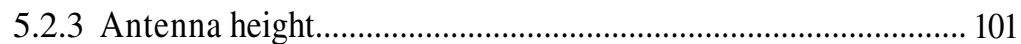

5.3 PROPAGATION MEASUREMENTS AND MODEL TUNING....... 102

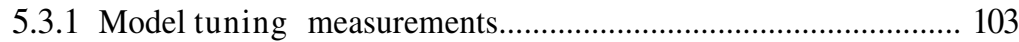

5.3.2 Model tuning process...................................................................... 104

5.3.3 Model tuning in a planning system.............................................. 107

5.3.3.1 Measurement import.................................................................... 107

5.3.3.2 Basic path loss model..................................................................... 108

5.3.3.3 Morphology corrections.................................................................. 109

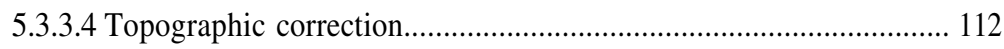

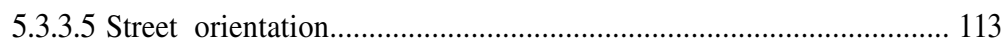

5.3.3.6 Tuning of morphology correction parameters........................................... 114

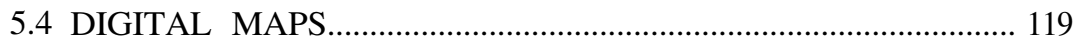

5.4.1 Quality criteria for digital map................................................120

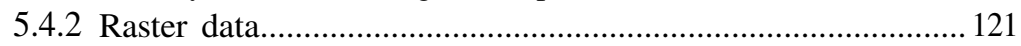

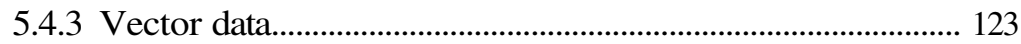

5.5 MICRO LEVEL MODELS........................................................... 123

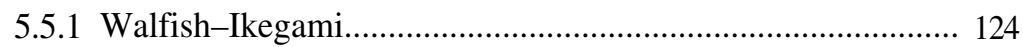

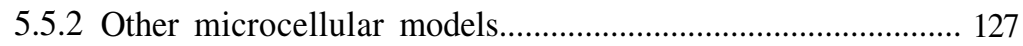

5.6 COVERAGE PLANNING PARAMETERS ..................................... 127

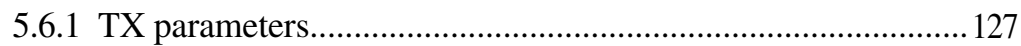

5.6.2 Calculation area....................................................................... 129

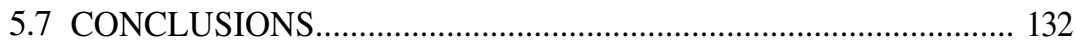

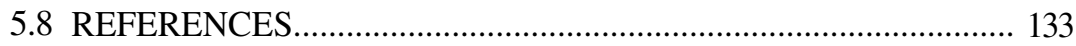


6. CAPACITY PLANNING...........................................................................136

6.1 CAPACITY PLANNING OVER A CERTAIN AREA...................... 137

6.2 TRAFFIC MODELS................................................................. 139

6.3 FREQUENCY REUSEFACTOR FOR THE MACRO BASE

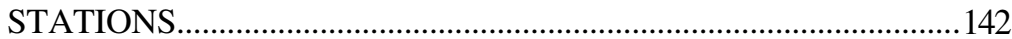

6.3.1 Frequency reuse factor............................................................. 143

6.3.2 Frequency reuse factor and co-channel carrier-to-interference

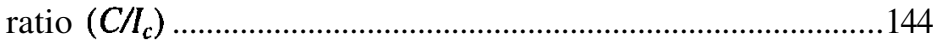

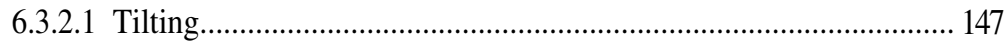

6.3.2.2 Software features.......................................................................... 148

6.4 MICROCELLULAR LAYER....................................................... 150

6.5 ADDITIONAL CAPACITY RELATED FUNCTIONS ................... 151

6.6 CONCLUSIONS................................................................. 152

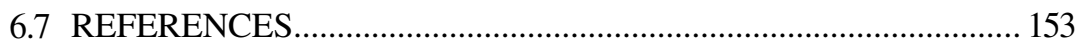

7. FREQUENCY PLANNING......................................................................156

7.1 FREQUENCY PLANNING CRITERIA.......................................... 156

7.2 INTERFERENCE ANALYSIS AND INTEREFERENCE

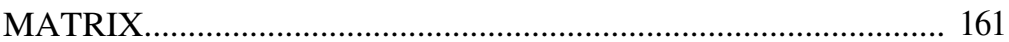

7.3 AUTOMATIC FREQUENCY PLANNING(AFP)......................... 164

7.4 ADDITIONAL FEATURES IN FREQUENCY PLANNING ......... 166

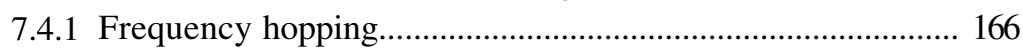

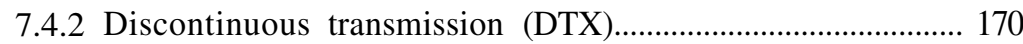

7.4.3 Power control............................................................................. 171

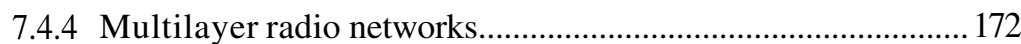

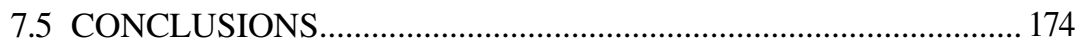

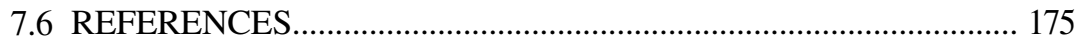

8. OPTIMISATION...........................................................................................178

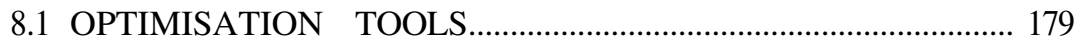

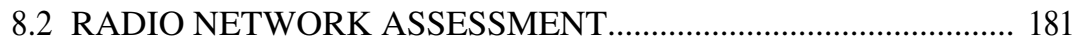

8.2.1 Coverage assessment.............................................................. 181

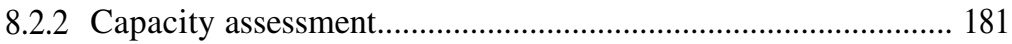

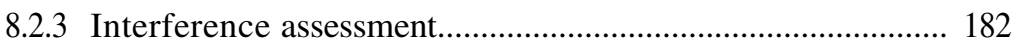

8.2.4 Functionality assessment......................................................... 182

8.3 RADIO NETWORK VERIFICATION AND TUNING ..................... 182

8.3.1 Coverage limited configuration management............................ 183 
8.3.2 Capacity limited configuration management.............................. 184

8.3.3 Interference verification and tuning ………………………....... 186

8.3.4 Radio network functionality verification and tuning (BSS radio

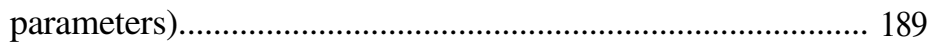

8.3.4.1 BTS $\Leftrightarrow$ MS signalling................................................................ 190

8.3.4.2 Radio resource management......................................................... 197

8.3.4.3 Mobility management...................................................................... 202

8.3.4.4 Measurements and measurement processing.................................... 203

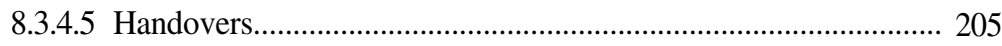

8.3.4.6 Power control........................................................................................ 207

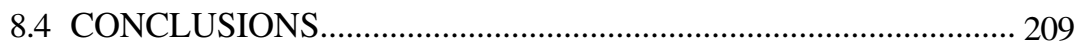

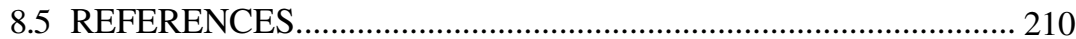

9. RADIO NETWORK MONITORING.......................................................212

9.1 RADIO NETWORK FUNCTIONALITY....................................... 212

9.1.1 Key performance indicators .................................................... 212

9.1.1.1 Radio network cost-efficiency......................................................... 213

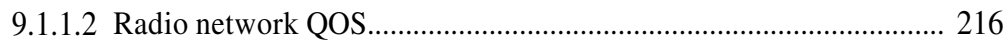

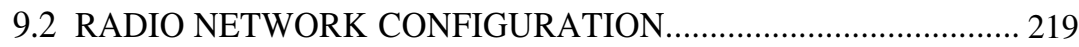

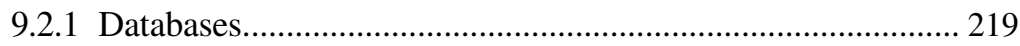

9.3 SOFTWARE PROGRAMS FOR MONITORING............................. 221

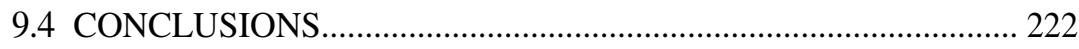

10. GENERAL PACKET RADIO SYSTEM (GPRS)..................................224

10.1 INTRODUCTION TO THE GPRS RADIO NETWORK................. 226

10.1.1 BSS related GPRS elements................................................ 227

10.2 GPRS RADIO PLANNING......................................................... 230

10.2.1 GPRS coverage planning criteria and thresholds ................... 230

10.2.2 GPRS capacity planning...................................................... 233

10.3 GPRS RELATED RADIO NETWORK FUNCTIONALITIES....... 237

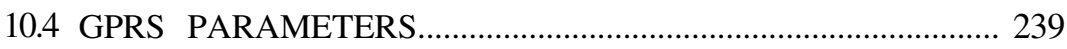

10.5 GPRS MONITORING............................................................. 240

10.6 ENHANCED DATA RATES FOR GSM EVOLUTION (EDGE).. 241

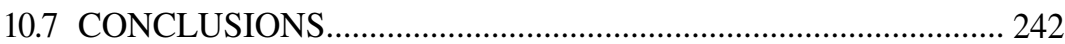

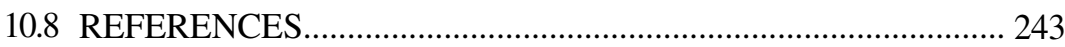




\section{UNIVERSAL MOBILE TELECOMMUNICATION SYSTEM}

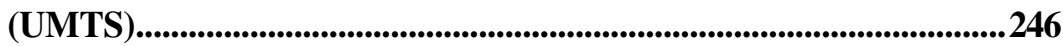

11.1 INTRODUCTION TO UMTS ........................................................ 246

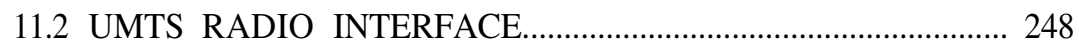

11.2.1 WCDMA air interface specification...................................... 248

11.2.2 Propagation environment..................................................... 250

11.2.3 Receiver performance....................................................... 254

11.3 UMTS RADIO SYSTEM PLANNING........................................ 258

11.3.1 UMTS radio system planning process..................................... 258

11.3.2 WCDMA configuration planning.......................................... 260

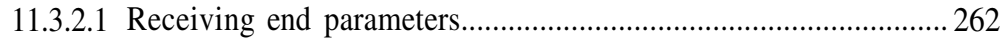

11.3.2.2 Transmitting end.................................................................. 265

11.3.2.3 Isotropic path loss...................................................................... 265

11.3.3 WCDMA coverage and capacity planning ............................. 266

11.3.4 WCDMA propagation prediction and coverage planning...... 267

11.3.5 WCDMA planning margins and coverage thresholds............. 267

11.3.6 WCDMA capacity planning.................................................. 268

11.3.7 WCDMA code and frequency planning................................ 271

11.3.8 WCDMA optimisation and monitoring................................. 271

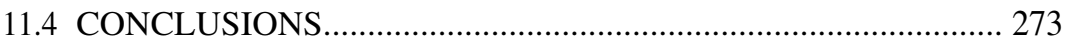

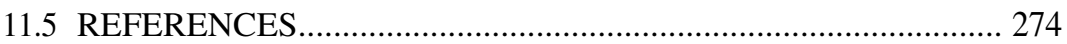

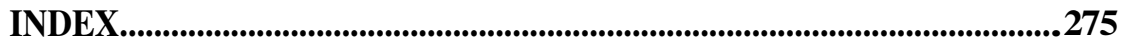




\section{PREFACE}

There are plenty of books written for academic courses about the areas of electromagnetics, radio technology or radio communications. In these books all the basic and more of the advanced mathematical and technical engineering principles about the theory of electromagnetics-reflections, diffractions, scattering, coupling-antennas and radio propagation-are explained. There are also many books concerned only radio communications and especially mobile communication systems. These books explain theoretical aspects of mobile communication systems in more detail but do not focus on the connections between different technical details. System level engineering is thus not addressed because it is typically thought only to be a practical issue. However, this system level understanding is a critical issue in today's mobile communications systems in order to achieve cost efficient and high quality radio engineering in mobile systems' radio interface. It is not enough to understand just technical details because these are connected to other technical aspects and these can all be combined in many different ways.

These various technical combinations within this mobile communications branch can be demotivating, particularly to newcomersnew RF engineers-who already know all the basics of radio technology because they have read all the basic books. Moreover, new engineers are often confused with all the different solutions for the different problems when they start learning the mobile communications principles and they can easily feel frustration because system level planning is a new and quite poorly documented topic. Hence, a simple and clear handbook about the radio planning principles and their connections in mobile communications systems is required to explain this system level planning.

This book is a part of the solution to understanding detailed technical radio engineering principles for mobile communication systems where all the details have a straight connection with each other. This book tries to bind very detailed pieces of technical information to the system level of thinking and thus to show the correct path at the junction. Mobile communication is full of these junctures because almost all the products are new, and technical development work is only just started. This handbook has been produced mainly with examples from the Global System for Mobile Telecommunication (GSM) because it is one of the most "global" standards (implemented over 80 countries). There are also many technical topics to be developed for the GSM during the next 
decade when GSM as a system is combined together with the Universal Mobile Telecommunication System (UMTS) that will be the next GSM compatible standard. The GSM examples in this book, and most of the technologies utilized in the GSM, can also thus be applied in the UMTS. Clear technical differences in the radio system planning between GSM and UMTS system are be explained and discussed in the concluding chapters 10 and 11 but otherwise there is no need to explain the variations between GSM and UMTS in technical detail here because this is covered in several other books. The main purpose of this handbook is to explain the radio interface system planning in the GSM (including GPRS) and to give the main instructions to continue the same work in the UMTS.

The content of this book is based on the radio system planning process that contains different phases that are explained in Chapters 3-9. Before these detailed planning phases Chapter 1 gives an introduction to the radio propagation environment in order to convey the influence of the environment on the radio system planning principles. The whole radio system planning process is also explained separately in Chapter 2 and Chapters 3-9 following the content of Chapter 2 at a detailed level. Radio system planning starts from configuration planning (Chapter 3) and continues with coverage planning (Chapters 4 and 5), capacity planning (Chapter 6), frequency planning (Chapter 7) and optimisation and monitoring (Chapters 8 and 9). Chapter 3 considers the definitions of the power budget calculations; the coverage planning done in Chapters 4 and 5 is based on the defined power budget from Chapter 3. Chapter 6 considers the capacity of the radio interface and Chapter 7 contains the frequency planning aspects. Chapters 8 and 9 give instructions on observing the performance of the planned radio system/network. Finally, Chapters 10 and 11 explain the detailed radio planning differences of the speech orientated GSM radio network and the packet transferred data GPRS/EDGE and the third generation UMTS radio networks.

Jukka Lempiäinen

Matti Manninen

Helsinki, July 2001 